\title{
CRÍTICA DA RAZÃO NACIONAL-OCIDENTALISTA: POR UMA NOVA ABORDAGEM PÓS-COLONIAL NOS ESTUDOS BRASILEIROS'1
}

CRITIQUE OF THE NATIONAL-OCCIDENTAL REASON: FOR A NEW POSTCOLONIAL APPROACH INTO BRAZILIAN STUDIES

\author{
Alfredo Cesar Melo \\ ORCID 0000-0002-7038-5749 \\ Universidade Estadual de Campinas \\ Campinas, SP, Brasil
}

\begin{abstract}
Resumo
Diante da intensa resistência à crítica pós-colonial dentro dos estudos brasileiros, este artigo procura organizar a discussão sobre o pensamento pós-colonial no Brasil, estruturando e situando qual seria o seu principal objeto de estudo. De acordo com o argumento desenvolvido ao longo do artigo, a experiência pós-colonial no Brasil é narrada hegemonicamente pelo intelectual nacional-ocidental (o artífice da dialética entre o local e o universal), que sempre atesta uma filiação à tradição ocidental ao mesmo tempo que afirma um desejo por demarcaçáo da singularidade nacional, onde estaria positivada a diferença entre o país e o centro de poder ocidental. Mostro no artigo que esse modo nacional-ocidental de articular o pós-colonial reproduz profundas lógicas de colonialidade. A partir da crítica dessa razão nacional-ocidental, proponho uma outra estruturação do pós-colonial nos estudos brasileiros.
\end{abstract}

Palavras-chave: Nacional-ocidental, Pós-colonial, Pensamento social brasileiro, Colonialidade

\begin{abstract}
Given the intense resistance towards postcolonial critique within Brazilian Studies, this article intends to organize the discussion about the postcolonial thought in Brazil, structuring it and situating what would be its main object of study. According to the argument developed in this article, the postcolonial experience is narrated hegemonically by
\end{abstract}

\section{Résumé}

Cet article vise à organiser la discussion sur la pensée post-coloniale au Brésil, vis-à-vis de l'intense résistance à la critique post-coloniale au sein des études brésiliennes, en structurant et en situant ce qui serait son principal objet d'étude. Selon l'argument développé tout au long de l'article, l'expérience post-coloniale au Brésil est racontée hégémoniquement

\footnotetext{
1 Este artigo foi escrito durante um estágio pós-doutoral na Universidade Nova de Lisboa, financiado pela Coordenação de Aperfeiçoamento de Pessoal de Nível Superior (Capes). O tema da nossa investigação era a ideologia do progresso no Brasil. Em um momento de crise e ameaça à existência das agências federais de fomento, reitero meu agradecimento à Capes.
} 
the national-occidental intellectual (the craftsman of the dialectics between the local and the universal). This intellectual frequently claims filiation to the Western tradition whilst also affirming the desire to demarcate the national singularity, turning positive the difference between his marginal country and the center of Western power. In this article I intend to show that the national-occidental way of articulating the postcolonial replicates the profound logic of coloniality. Based on this critique of the national-occidental reason, I offer an alternative structuration to the postcolonial question within Brazilian Studies.

Keywords: National-occidental, Postcolonial, Brazilian social thought, Coloniality par l'intellectuel national-occidental (l'artisan de la dialectique entre le local et l'universel), qui rend compte d'une affiliation avec la tradition occidentale en même temps qu'il affirme une volonté de démarcation de l'unicité nationale, dans laquelle la différence entre le pays et le centre du pouvoir occidental serait perçue comme positive. Je montre dans l'article que cette façon nationale-occidentale de penser le post-colonial reproduit les logiques profondes de la colonialité. Sur la base de la critique de cette raison nationale-occidentale, je propose une autre structure du post-coloniale au coeur des études brésiliennes.

Mots-clés: National-occidental, Postcolonial, Pensée sociale brésilienne, Colonialité

Se os estudos pós-coloniais se definem pela reflexão em torno do legado colonial, seus efeitos e prolongamentos nos campos da economia, da cultura, da política e das relaçóes sociais, não se pode negar que há, no âmbito brasileiro, uma longa tradição de pensamento e crítica pós-coloniais. É óbvio que a maneira como esse campo de estudo se estrutura no Brasil pouco tem a ver com o que se denomina postcolonial studies nos países de língua inglesa. A experiência da descolonização após a II Guerra Mundial deu o lastro a essa teorização pós-colonial nas academias norte-americanas e inglesas, levada a cabo por intelectuais originários das ex-colônias europeias (Edward Said, 1978; Homi Bhabha, 2000; Gayatri Spivak, 1999; Dipesh Chakrabarty, 2000; Hamid Dabashi, 2015; Gyan Prakashi, 1999) e focada na dualidade instável, ambivalente e porosa entre colonizador e colonizado, ocidental e oriental, centro e periferia, primeiro e terceiro mundos.

A singularidade de cada experiência colonial, ao longo do tempo e do espaço, náo permite que um caso possa servir de paradigma iluminador para o outro. É preciso urgentemente provincianizar ${ }^{2}$ os estudos pós-coloniais, isto é, compreender as reflexóes críticas sobre os efeitos do colonialismo,

2 A referência aqui é ao estudo clássico de Dipesh Chakrabarty, Provincializing Europe. Provincianizar a Europa seria questionar sua posição de locus enunciador da universalidade, isto é, seria apontar a particularidade que se quer - e que por meio do poder político, econômico, militar e cultural, se faz universal. 
em suas diferentes configuraçóes históricas e políticas, como um arquivo de saberes pós-coloniais (com potencial descolonizante), que deve estar à disposição de todos, sem modelos normativos centrados em países específicos a serem seguidos - o que inevitavelmente estabeleceria uma hierarquia entre experiências coloniais -, nem tampouco devemos estimular a reprodução da divisão internacional do conhecimento, na qual ao centro compete teorizar e a periferia cabe o papel de objeto a ser teorizado. É preciso encontrar uma tensão dialógica entre os diferentes modos de pensar o pós-colonial ao redor do globo, que são a um só tempo desiguais e combinados, diferentes e familiares, singulares e conectados.

Parto do princípio, portanto, de que o pós-colonial não é apenas múltiplo geografica e historicamente (as experiências coloniais - e a consequente reflexão sobre elas - são variadas ao longo do espaço e do tempo), mas também sociologicamente. Dentro de um espaço pós-colonial, há visōes díspares sobre o que foi a experiência colonial, e se o seu legado deve ser mantido, parcialmente apreciado ou totalmente eliminado. Este artigo pressupóe que o pós-colonial é um campo em permanente disputa ${ }^{3}$, seja por parte de diferentes correntes ideológicas e intelectuais, seja por parte das diversas classes sociais e grupos étnicos, que vivenciam a colonialidade cada um a seu modo, limitados por seus condicionamentos. Para os efeitos do argumento aqui exposto, examinarei criticamente como se dá a dinâmica geral dessa disputa no segmento letrado, que exerce um papel hegemônico na construção de autoimagem do país, por meio das chamadas interpretaçóes do Brasil.

De acordo com a hipótese que pretendo desenvolver ao longo do artigo, o pós-colonial se configura entre os letrados brasileiros a partir de um sistema de possibilidades que denomino como arco nacional-ocidental. Tal sistema se estrutura a partir de polêmicas, tensionamentos e debates acerca da herança ocidental no Brasil, e da maneira como o "nacional" performaria variaçóes, apropriaçóes e modulaçóes em torno dessa herança, gerando um espaço de negociação identitária em que tanto os legados supostamente universais (sempre identificados com o Ocidente) como as singularidades da nação poderiam coexistir de um modo bastante compatível. Empregando um outro vocabulário teórico, apresento ao leitor a boa e velha dialética entre o local e o universal, instrumento analítico fundamental para os brasileiros darem inteligibilidade à experiência colonial e seus legados. $\mathrm{O}$ que proponho é investigar as dimensóes ocultas dessa dialética, e mostrar como o pós-

3 Nesse sentido, năo há como discordar de Quentin Skinner, que a força estruturante da história das ideias é a batalha ideológica e intelectual: "[T]he principles governing our moral and political life have generally been disputed in a manner more reminiscent of the battlefield than the seminar room. [...] What the historical record strongly suggests is that no one is above the battle, because the battle is all there is." (SKINNER, 2002, p. 7). 
colonial do letrado brasileiro repóe inúmeras lógicas de colonialidade, isto é, de hierarquização e subalternização de culturas não ocidentais.

Por fim, uma nota metodológica: considero aqui o denominado "pensamento social brasileiro" de uma maneira descritiva, isto é, como um conjunto de textos produzido por um campo caracterizado na época pela pouca especializaçáo intelectual e diferenciação disciplinar, no qual podemos encontrar obras de literatura, de crítica literária, o ensaio sociológico e antropológico, as sínteses históricas, as reflexôes filosofantes. Esses textos almejavam não apenas construir representaçóes da sociedade e cultura brasileiras, devendo ser também compreendidos como atos de fala que performam disputas em torno do que o Brasil deveria ser, de sua relaçáo com as instituiçóes ocidentais, de que ideias parecem se adequar ou não ao território nacional, etc. Não pretendo fazer qualquer avaliação sobre o potencial teórico (LYNCH, 2013) ou sobre a eficiência explicativa de tais textos (TAVAROLO, 2014), encarando-os sobretudo como elementos constitutivos de um sistema de significação das possibilidades da nação.

\section{Enfrentando a doença de Nabuco}

No Brasil, a dinâmica da sociedade pós-colonial que se estabeleceu era muito distinta daquela encontrada em vários países da África e da Ásia do pós-guerra, e como notava Paulo Emílio de Salles Gomes, as figuras dos ocupantes e ocupados tornaram-se relativamente indistintas ao longo dos séculos de colonização, a ponto de, ainda segundo Paulo Emílio, não haver, entre a nação brasileira e o ocidente, "a barreira natural de uma personalidade hindu ou árabe"(1980, p. 76), que precisasse "ser conscientemente sufocada, contornada e violada”(1980, p. 76). Na Argélia, lembra Paulo Emílio, os franceses foram expulsos do país após a descolonização, o que representaria uma "aberração sociológica" se a mesma medida fosse aplicada à situação brasileira. Em linha semelhante de raciocínio, Roberto Schwarz argumenta que os brasileiros “já não somos mais os índios e africanos da primeira época, de modo que há também ingenuidade e mitificação em considerar o colonizador como o outro, com quem nós, povos colonizados, não temos parte" (1999, p. 71, grifos do autor). Tanto os brasileiros teriam parte com o colonizador que, para retornar à elaboração de Paulo Emílio, seriam vistos como um "prolongamento do Ocidente"(1980, p. 76), habitando a América com valores e preceitos europeus, o que os fazia muitas vezes se sentirem, na definição de Sérgio Buarque de Holanda, "desterrados na própria terra"(1995, p. 17). A configuração póscolonial gerava no letrado brasileiro essa sensaçáo perene de deslocamento, isto é, de alguém que vive na periferia do ocidente, em comunhão espiritual com a Europa, mas segregado do seu centro dinâmico de poder e criação cultural. Não é por acaso que Antonio Candido define a literatura brasileira 
como "galho secundário da [literatura] portuguesa, por sua vez, arbusto de segunda ordem no Jardim das Musas" (1997, p. 9). Retrato eloquente desse mal-estar pode ser encontrado nas palavras célebres de Joaquim Nabuco, para quem o espírito humano fazia do continente europeu a sua morada, deixando os habitantes do Novo Mundo numa "verdadeira solidão, tão longe das suas reminiscências, das suas associaçóes de ideias, como se o passado todo da raça humana se lhe tivesse apagado da lembrança" (1998, p. 59).

O historiador Evaldo Cabral de Mello aponta corretamente que o grande esforço intelectual do século 20 brasileiro esteve concentrado na tentativa de cicatrizar as feridas da doença de Nabuco (MELLO, 2002, p. 120). Tal esforço pode ser verificado no modo como o nacionalismo cultural modernista tornou-se um vetor hegemônico na interpretação que os brasileiros construíram para dar inteligibilidade a esses dilemas. $\mathrm{O}$ desafio era equacionar de modo favorável à autoestima nacional a inelutável dependência cultural (resultado da posição periférica do Brasil no sistema internacional) com a capacidade de afirmação e criação artística do país. Em outras palavras, era imperativo buscar uma síntese entre "prolongamento e novidade; cópia e invenção; automatismo e espontaneidade" (CANDIDO, 1987, p. 192). Ou para usar o vocabulário crítico de Silviano Santiago, fazia-se necessário achar um espaço entre "prisão e transgressão. [...] submissão ao código e agressão; [...] obediência e rebelião; [...] assimilação e expressão" (SANTIAGO, 2000, p. 18). Os intelectuais deviam examinar quais seriam os possíveis espaços de manobra deixados pela moldura civilizatória ocidental para a expressão criativa e singular dos brasileiros.

Não seria exagero afirmar que boa parte dos anseios pós-coloniais da inteligência brasileira ao longo do século 20 esteve em teorizar a contribuição específica do local (Brasil) ao repertório universal (Ocidente), além de conceber uma modulaçáo localista da cultura ocidental. De acordo com a expressão de Mário de Andrade, tratava-se de achar um acorde que fosse usado na harmonia da civilização ocidental (ANDRADE, 1982, p. 15). Na crítica cultural, esse empenho pode ser encontrado em estudiosos das mais distintas correntes teóricas, o que mostra que o problema é estruturante e de base. Para Antonio Candido, "nossas literaturas são essencialmente europeias, na medida em que continuam a pesquisa da alma e de sociedade definida na tradiçáo das metrópoles" (1987, p. 195). No entanto, por estarem transplantadas em ambiente estranho, em contato com outros povos e tradiçôes, essa literatura "foi obrigada a imprimir na expressão herdada certas inflexões que a tornaram capaz de exprimir também a nova realidade natural e humana" (1987, p. 195). De acordo com tal argumento, o Brasil seria capaz de imprimir inflexóes no texto metropolitano e de criar variaçóes inventivas da cultura ocidental. Algo semelhante pode ser encontrado em Haroldo de Campos, que defendia 
um nacionalismo modal (em contraposição ao nacionalismo ontológico, atribuído ao modelo historiográfico de Formação da literatura brasileira), que é pensado como "movimento dialógico da diferença" (1981, p. 17), capaz de produzir tal diferença "nos interstícios de um código universal" (1981, p. 19). Silviano Santiago, por sua vez, teoriza sobre esse estatuto secundário ou derivativo geralmente associado às culturas periféricas como a brasileira. Combatendo as noçóes de fonte e influência - que haviam marcado até entáo a disciplina da literatura comparada -, Santiago argumenta que "[a] maior contribuição da América Latina para a cultura ocidental vem da destruição sistemática dos conceitos de unidade e pureza" (2000, p. 16). Santiago defende assim uma ideia de "universalidade diferencial", que se contrapóe aos valores estáticos e monológicos da "universalidade dos colonizadores" (1980, p. 42). A universalidade diferencial seria aquela em que o escritor latino-americano suplementa, comenta, adiciona, critica, retifica o texto metropolitano, num diálogo em que destaca a diferença e descarta qualquer tipo de submissão.

Apesar das divergências teóricas que existem entre esses autores; das inúmeras polêmicas historiográficas travadas entre eles sobre as origens e formação da literatura brasileira; das discordâncias políticas sobre o sentido dessa modulaçáo nacional da cultura ocidental; pode-se dizer que, ao longo do século 20 , a crítica brasileira construiu um modelo explicativo sobre a produção cultural brasileira em que o local é, a um só tempo, parte integrante do "universal" e elemento capaz de reelaborar e reinventar as feiçóes da tradição cultural ocidental tais como se manifestam naquele local do planeta - às vezes de modo rebelde e inconformista, outras tantas de modo harmonioso e funcional. Para sintetizar recorrendo ao título de famoso artigo de Silviano Santiago, poderíamos dizer que a crítica cultural esteve empenhada em mostrar que, ao longo do século 20, o Brasil poderia ser, "apesar de dependente, universal” (i.e., participar de maneira crítica e criativa na reelaboração da cultural ocidental, a despeito de sua posição periférica).

Se ao longo do século passado, a reflexão pós-colonial no Brasil se configurou a partir de um dilema que era essencialmente do letrado brasileiro (espremido por sua dupla fidelidade, seus ambivalentes sentimentos de pertença, etc.), o momento histórico atual - travejado por demandas de grupos historicamente excluídos da cidade letrada, como os movimentos negros e os povos ameríndios - é propício tanto para o questionamento desse letrado nacional-ocidental quanto para sugerir a reflexão sobre uma outra estruturação do pós-colonial no Brasil. A proposta deste artigo é transformar o sujeito pós-colonial hegemônico do cenário brasileiro - o artífice da dialética entre o local e o universal, isto é: o intelectual nacional-ocidental - num objeto a ser examinado criticamente. A questão pós-colonial no Brasil vem sendo basicamente estruturada a partir da narrativa tecida por esse sujeito, 
que realça o dilema do mazombo, a doença de $\mathrm{Nabuco}^{4}$, ou que imagina a cultura brasileira metaforicamente como sendo um tupi tangendo o alaúde, ou um antropófago devorando a Europa, habitando entrelugares variados. $\mathrm{O}$ foco do presente estudo náo incidiria sobre aquilo que o letrado pós-colonial brasileiro afirma e recria dentro do espaço possível das estruturas ocidentais, mas sobre o que tal sujeito nega e suprime em nome dessas estruturas que o abrigam e da qual participa, ainda que de uma maneira supostamente crítica e rebelde. É preciso entender o que viria a ser e como funciona aquilo que denomino o arco discursivo nacional-ocidental para esmiuçar essas relaçóes de poder.

\section{O arco nacional-ocidental}

Antes de apresentar o conceito de nacional-ocidentalismo, caberia avaliar a ideia de ocidentalismo, que já há algum tempo circula nos estudos pós-coloniais hispano-americanos. De acordo com o antropólogo venezuelano Fernando Coronil (1996), o ocidentalismo não poderia ser interpretado como o reverso do orientalismo (isto é, uma representação estereotipada do Ocidente produzida pelos orientais) porque a imagem estigmatizada ou caricatural do Ocidente eventualmente criada por orientais está longe de afetar a vida dos ocidentais, enquanto o orientalismo estrutura políticas públicas e modos de atuação estatal e empresarial que reverberam no cotidiano daqueles que são "representados" em tal discurso. Isso dito, ainda segundo Coronil, ocidentalismo poderia ser interpretado como a própria condição de possibilidade do orientalismo. Afinal, se o orientalismo é uma formação discursiva ocidental que inventa o Oriente, tal fabricação da alteridade só faz sentido quando contraposta à autoimagem do seu criador, o intelectual ocidental. O pressuposto da representação do Outro oriental seria a elaboraçáo de parâmetros definidores da diferença abissal entre o objeto oriental representado e o sujeito ocidental, sempre marcado por sua suposta superioridade racial, excepcionalismo cultural, além dos fardos e missóes civilizatórias autoatribuídas. Esse conjunto de prerrogativas e autopercepçóes formaria o núcleo do ocidentalismo.

De acordo com Walter Mignolo, as Américas - diferentemente do Oriente - não seriam vistas (e autorrepresentadas) como o outro da Europa (2000, p. 97). O Novo Mundo seria compreendido como uma extensão do Velho Continente. Isso faz com que o ocidentalismo seja uma questão

4 Mazombo seria o luso-descendente nascido no Brasil, na época da colonizaçấo. O dilema do mazombo, nas palavras de Evaldo Cabral de Mello, seria o dilema do "descendente de europeu ou reputado como tal, com um pé na América e outro na Europa, e equivocadamente persuadido de que, cedo ou tarde, terá de fazer uma opção" (MELLO, 2002, p. 130). A doença de Nabuco seria basicamente uma variaçấo do dilema de mazombo. 
pertinente aos países americanos - já que a América seria desenhada nesse mapa imperial como o extremo Ocidente. É claro que tal autoimagem se configura de modo bastante diferente quando comparamos o que acontece no centro de poder do Ocidente com o que ocorre nas suas margens. $\mathrm{O}$ ocidentalismo de um administrador colonial britânico ou de um diplomata francês apresenta uma outra dinâmica de poder quando cotejado ao modo de imaginar-se ocidental encontrado no discurso de um publicista brasileiro ou de um ensaísta argentino. Enquanto os primeiros são parte de um projeto imperial, os ocidentais periféricos estão engajados no processo de consolidação do Estado nacional. Apesar da imensa disparidade na escala geopolítica de suas atuaçóes, tanto o administrador colonial francês quanto o ensaísta latino-americano precisam enquadrar um outro para afirmarem a hegemonia ocidental nos cenários em que trabalham ${ }^{5}$. No caso brasileiro, os outros seriam: o negro, o índio, as formas de vida consideradas tradicionais e arcaicas dos caipiras, dos sertanejos, dos quilombolas, vistas como impróprias para os bons hábitos de trabalho, para a produtividade da economia, e para o exercício de uma cidadania plena. Um conjunto de obstáculos gerado pela presença não ocidental precisaria ser removido, suavizado, diluído ou domesticado para a nação se modernizar.

Tal como se manifesta nos países latino-americanos, o ocidentalismo está, portanto, intrinsecamente ligado à questão nacional. Não há a menor dúvida que essa relação extensiva com a Europa, de prolongamento e pertença, fartamente encontrada na imaginação letrada brasileira em vários momentos históricos, vem acompanhada de uma busca pela singularidade nacional. $\mathrm{O}$ que vale também destacar é que, para o letrado brasileiro, nacionalismo e ocidentalismo nunca foram forças em oposição ${ }^{6}$, como podemos verificar no início do artigo e em declarações como a do então presidente Fernando Henrique Cardoso:

5 Apesar de "imperialismo" ser um conceito muitas vezes tido como sinônimo de "colonialismo", é importante destacar que, quando o conceito é criado por John Hobson, o imperialismo é estudado como produto da competição frenética entre potências europeias por territórios e recursos naturais em escala planetária. O imperialismo se alimentaria portanto de uma espécie de nacionalismo hipertrofiado das potências europeias. Também devemos notar que se, ao longo do século 19, o imperialista europeu tinha que enquadrar o "outro" em territórios muito distantes da Europa, no século 20, o quadro muda substancialmente a paritr da migração de habitantes das ex-colônias para os espaços metropolitanos. A reação racista a essa onda migratória foi bem analisada por Etienne Balibar e seu conceito de "neoracismo" (cf. BALIBAR, 1991).

6 Observando o processo de modernizaçáo e padronização geral do mundo, sobretudo após a II Guerra Mundial, Erich Auerbach observa que tal processo homogeneizador não encontra no nacionalismo uma força de oposiçāo: "Por mil razōes, conhecidas por todos, a vida humana uniformiza-se em todo planeta. $\mathrm{O}$ processo de nivelamento, originário da Europa, estende-se cada vez mais e soterra todas as tradiçóes locais. É certo que, por toda parte, o sentimento nacional é mais forte e barulhento do que nunca, mas em toda parte ela toma a mesma direçáo, isto é, rumo às modernas formas de vida" (AUERBACH, 2007, p. 357). 
Nós aqui somos [...] extremo Ocidente, mas no extremo Ocidente a presença não ocidental existe. E nós só queremos constatá-la no geral, mas não aspiramos criar um modelo para o mundo que seja alternativo ao Ocidente. A Índia talvez aspire. Queremos, sim, ter um espaço nesse modelo do Ocidente para algumas peculiaridades, e a Índia talvez queira outra coisa que não o Ocidente, como a China. (2015, p. 417)

Notemos que o desejo por um espaço para afirmar "algumas peculiaridades" e a constatação da presença "não ocidental" do Brasil em nada mexem com a disposição brasileira de, nas palavras de Cardoso, não "criar um modelo para o mundo que seja alternativo ao Ocidente". Estamos novamente no terreno discursivo da "modulação", da "variação", do "espaço de manobra" possível, da "inflexão local”, isto é, da gestão nacional de uma cultura que almeja alguma singularidade, ainda que completamente compatível com os quadros gerais da civilização ocidental ${ }^{7}$.

Uma reflexão do historiador Fernando Novais talvez ajude a pensar nas condiçóes históricas de emergência desse sistema de possibilidades que denominamos aqui de nacional-ocidental. Segundo Novais:

Para entender a cultura brasileira, nós temos que pensar que a Independência foi feita pelo senhoriado colonial, que não é nem o colonizado, nem o colonizador, como já dissemos. Se nós não partirmos disso, não entendemos que a cultura brasileira é uma cultura que se debate na procura de uma identidade difícil de se caracterizar. Porque, ao fazer a Independência, você não pode se identificar com o colonizado, que é o índio e o negro, porque você quer continuar colonizando, mas também não pode se identificar com o colonizador, que é

\footnotetext{
7 São inúmeras as formulaçóes sobre essa compatibilidade estrutural entre o ocidente e a nação na cultura brasileira, isto é, sobre esse jogo dialético que envolve pertencimento ao Ocidente e certa diferenciação formuladora da singularidade nacional, mas que náo rejeitaria o vínculo espiritual com o Ocidente. Só a título de exemplo, vejamos o editorial da Revista, periódico modernista de Minas Gerais, editado por Carlos Dummond de Andrade (entre outros): "Será preciso dizer que temos um ideal? Ele se apoia no mais franco e decidido nacionalismo. A confissáo desse nacionalismo constitui o maior orgulho de nossa geraçâo, que náo pratica a xenofobia nem o chauvinismo, e que, longe de repudiar as correntes civilizadoras da Europa, intenta submeter o Brasil cada vez mais ao seu influxo, sem quebra da nossa nacionalidade original" (citado em MARQUES, 2013, p. 36). Por outro lado, há os argumentos que mostram a compatibilidade de um certo Ocidente (o ibérico) com os países latino-americanos. José Guilherme Merquior na sua reflexão sobre o "outro Ocidente" do qual os países como o Brasil faziam parte, reconhece que os latino-americanos "somos uma modificação e uma modulação original e vasta da cultura ocidental. Mas isso a Ibéria sempre foi: um caso peculiar do Ocidente, porém de forma alguma uma aberração. A Ibéria sempre foi uma faceta especial a Hespéria - e assim somos nós, criaturas da Ibéria e gênios da mistura étnica e cultural (MERQUIOR, 1990, p. 36). Apesar do reconhecimento que o Brasil faz parte de um outro Ocidente, Merquior em nenhum momento defende uma "alternativa latino-americana". Pelo contrário, o artigo parte de uma crítica ao O espelho de Próspero de Richard Morse e seu elogio à tradição cultural ibérica. Como liberal, Merquior é um árduo defensor da modernizaçấo social e econômica brasileira, que nos deixaria mais próximos do Ocidente hegemônico.
} 
o português, porque senão você não faz a Independência. É isso que cria o drama da cultura brasileira, náo só o drama político (2004, p. 139).

Como não é propriamente um colonizador nem um colonizado, esse senhoriado (pós-) colonial precisa se diferenciar da cultura metropolitana, a portuguesa, construindo os símbolos próprios da nação, ao mesmo tempo que quer continuar a colonização de negros, índios e mestiços. Manter a colonização, nesse caso, deve ser compreendido tanto no sentido de continuar subjugando e explorando economicamente essas populaçóes para se inserir de maneira competitiva no mercado internacional de gêneros primários (dentro da lógica agromercantil), como no sentido de "civilizar" esses povos, incutindo padrôes sócio-culturais ocidentais com o objetivo de modernizar o povo brasileiro (seguindo a lógica progressista). Os dois modos de "continuar colonizando" não deixam de ser, cada um à sua maneira, e seguindo um figurino próprio, formas de integrar os "colonizados" ao Ocidente ${ }^{8}$. Daí podemos apreender nessa posição estrutural do senhoriado pós-colonial brasileiro as condiçóes históricas de possibilidade para o nexo entre nacionalismo (que pretende se diferenciar da ex-Metrópole) e ocidentalismo (que pretende integrar o povo brasileiro ao Ocidente, seja dentro da lógica agromercantil, seja dentro da retórica progressista). A observação de Fernando Novais é particularmente enriquecedora porque ela dá uma maior precisão sociológica à questão, destacando um grupo social relativamente homogêneo que domina a narrativa pós-colonial no Brasil, que como vimos, se concentra nos diversos modos de se imaginar nacional-ocidental.

A mais conhecida formulação da dinâmica nacional-ocidental se encontra na dialética entre o local e o universal, eloquentemente elaborada por Antonio Candido a ponto de virar um lugar-comum acadêmico. Ao enunciar a tensão entre dado local (substância de expressão) e os moldes herdados da tradição europeia (forma de expressão) como possível "lei de evolução da nossa vida espiritual" (2000, p. 117), Antonio Candido também faz uma aposta no equilíbrio entre o local e o universal como definidor do "que temos realizado de mais perfeito" no âmbito das obras literárias e das personalidades artísticas de seus escritores (2000, p. 117). Como a tensão entre a matéria brasileira e a forma europeia que a amolda está no centro da imaginação nacional, longe,

8 No seu Dialética da Colonização, Alfredo Bosi disserta sobre a tensão existente entre os jesuítas e bandeirantes no início da colonização portuguesa na América, que nada mais era que uma disputa sobre os modos de colonizar o índio. Para os jesuítas, o foco era a colonização da alma, isto é, a cristianização do índio; para os bandeirantes, o principal objetivo era o da colonização do corpo do índio, isto é, a sua força física para o trabalho escravo nas fazendas dos colonos portugueses. Chegou-se a estabelecer um acordo no qual os índios passariam 6 meses trabalhando na lavoura, e 6 meses nos aldeamentos dos jesuítas (BOSI, 1992, p. 138). É interessante notar como essa dinâmica acabou sendo atualizada dentro do sistema nacional-ocidental de possibilidades. 
portanto, de ficar circunscrita ao campo da literatura, era de se esperar que a harmonia entre o local e o universal também correspondesse a um esboço de perfeição em outros setores da sociedade. Escrevendo mais de vinte anos depois, Roberto Schwarz constata que a leitura em chave harmoniosa da dialética entre o local e o universal caiu em completo descrédito, o que não significa, ainda de acordo com o crítico, que os termos propostos tenham perdido a relevância, devendo ser assim redefinidos (1987, p. 169).

A nosso ver, a ilusão de que uma síntese equilibrada entre as forças locais e ocidentais conduziria os brasileiros ao concerto das naçôes civilizadas é resultado de uma leitura empobrecedora dos termos de tal dialética, incapaz de perceber suas ambivalências ideológicas e amplitudes semânticas. A maneira mais realista de compreender como funciona essa dialética é mapeando o campo discursivo em permanente estado de disputa que ela constrói. Isso quer dizer que termos como "nacional" e "ocidental" funcionam como significantes vazios, mobilizando grupos sociais, ideologias e instituições na constituição das equivalências vistas como adequadas para tais termos, além de articular demandas centrais da sociedade brasileira (secularismo x tradição religiosa; vocaçẫo rural $\mathrm{x}$ industrialismo; democracia $\mathrm{x}$ regimes tutelados, etc) ${ }^{9}$. Para uns, ocidente quer dizer "civilização cristã"; para outros, "valores seculares do Iluminismo". A nação pode ser compreendida por alguns como sendo sinônimo do negócio que a sustenta ("O Brasil é o café"; "O Brasil é o agronegócio", etc); enquanto, para outros, a nação seria (ou deveria ser) um contrato social baseado em ideais republicanos. Isso sem falar do discurso cultural em torno da nação: a busca pela nota específica da nossa singularidade - aquilo que distinguiria o estar no mundo do brasileiro - também geraria vários debates em torno do jeito brasileiro de ser, que pode ser malandro, macunaímaco, cordial, antropofágico, luso-tropical, tropicalista, etc. São vários - e por vezes conflitivos - os modos de imaginar a nação e sua participação no Ocidente, assim como a inserção dos chamados "valores ocidentais" na nação. $\mathrm{O}$ arco nacional-ocidental está longe de ser um bloco de doutrinas e ideias homogêneas vindo de um grupo social igualmente homogêneo com finalidade de dominar povos não ocidentais. As narrativas geradas por esse arco são múltiplas, conflitantes, por vezes antagônicas, ainda que, como veremos, limitadas. Por ter essa estrutura lacunar, de vazios que são preenchidos por grupos que disputam narrativas, o nacional-ocidentalismo não compartilha da mesma moldura conceitual do Orientalismo, frequentemente atacada por representar um conjunto de doutrinas sem grande variação diacrônica, que perpassa o pensamento europeu de Ésquilo a Flaubert, passando por Dante, Goethe, Disraeli, Ernest Renan e tantos outros (GELLNER, 1994; AHMAD, 1992).

9 O diálogo aqui é evidentemente com o modelo de Laclau to "significante vazio", cf. Laclau, 1996. 
Tais disputas podem ser explicadas pela configuração específica do Brasil após a Independência, conforme já pontuou Fernando Novais. Analisando pelo ângulo da vida ideológica propriamente dita, Roberto Schwarz identifica um "desajuste de base" que havia definido a situação do país. Os brasileiros entraram na modernidade pela porta dos fundos, mantendo uma estrutura econômica colonial para abastecer o mercado europeu e recorrendo ao escravismo - já naquela época considerado abjeto pela norma burguesa - como esteio sócio-econômico do país. Entrar pelas portas dos fundos da modernidade não representava obstáculo para que as elites brasileiras mantivessem contato com as ideias mais avançadas da época, que por vezes eram assimiladas de modo cínico e grotesco, compondo aquilo que Schwarz chama de "comédia ideológica". Já em outras ocasiôes, tais ideias ganhavam tração e se firmavam como horizonte inspirador nas lutas por transformaçóes sociais no Brasil. Em seu Dialética da colonização, Alfredo Bosi assinala esses momentos em que o Novo Liberalismo de Joaquim Nabuco e o positivismo social dos políticos gaúchos - primeiro grupo político a defender um Estado do Bem-Estar no Brasil - se contrapóem aos interesses particularistas das oligarquias rurais. A disputa pelo termo "Ocidente" está longe de ser uma querela meramente discursiva e se enraíza no irregular solo da história brasileira. Para uns, Ocidente significa o circuito de investimentos, produção de gêneros primários e mercado consumidor europeu, sedimentado no edifício cultural do patriarcalismo católico, que tornava possível a economia e a sociedade semicolonial brasileira. Para outros, Ocidente representa ideias de soberania nacional, industrialização e secularismo, servindo assim como inspiração para combater a subalternidade da economia brasileira no seu papel de fornecedora de mercadorias agrícolas e abraçar um projeto empoderado de Estado-Naçáo, capaz de alçá-lo ao concerto de naçóes civilizadas (europeias). Alfredo Bosi enxerga no conflito entre humanismo "universalista" (de sabor católico, liberal ou socialista, a depender do momento histórico) e os interesses agromercantis a grande mola da "dialética da colonização".

Afasto-me, em minha análise, da moldura valorativa que Bosi emprega para descrever tais conflitos entre ideais universalistas e compromissos particularistas, pois nem os compromissos das oligarquias rurais são táo particularistas - já que fazem parte do circuito internacional do capital e integram, ainda que de maneira subalterna, a economia brasileira à mundial -; nem a suposta universalidade dos ideais, como veremos, é tão benévola, pois muitas vezes pressupóe o achatamento das diferenças culturais. Reitero, no entanto, que as os conflitos e tensóes analisados por Bosi em Dialética da colonização traduzem bem as disputas em torno da ideia de naçáo e do modo de inseri-la no ocidente, e que tais conflitos advém da unidade dialética da própria colonização (tanto o humanismo cristáo de Vieira quanto os interesses 
mercantis dos bandeirantes são peças fundamentais da máquina colonial). Outros conflitos poderiam ser acrescentados a esse rol de disputas como, por exemplo, o debate entre o empresário Roberto Simonsen, árduo advogado do industrialismo, e o economista Eugênio Gudin, defensor da ideia de vocação agrária do Brasil. No século 19 poderíamos encontrar o caso, sobejamente comentado pela crítica cultural brasileira, do argumento conservador de que as ideias ilustradas e liberais seriam alienígenas em solo brasileiro e, portanto, estariam "fora do lugar" (SCHWARZ, 1977). Tal modo de conceber os locais apropriados e inapropriados para ideias liberais também faz parte do debate sobre que tipo de nação deveria ser o Brasil e que tipo de participação teria a cultura ocidental - de algum ocidente a ser definido, às vezes demonizado, outras tantas idealizado, mas sempre disputado - nos rumos do país.

Também é necessário esclarecer que apesar de muitas vezes ressaltar, para fins didáticos, as polaridades mais óbvias nesse conflito entre modernizadores industriais e oligarcas rurais, progressistas e conservadores, etc., seria um equívoco reduzir a dinâmica existente a esses dois polos, sendo a vida social e política brasileira tão pródiga em embaralhar posicionamentos ideológicos. Daí o cuidado de chamar de arco nacional-ocidental, que pressupóe uma disposiçáo espacial para gradaçóes e combinaçôes várias entre as múltiplas equivalências construídas para os termos em disputa.

$\mathrm{O}$ arco nacional-ocidental se apresenta entáo como um sistema autossuficiente de possibilidades, uma suposta totalidade por onde navega a imaginação política e cultural brasileira, da direita à esquerda; entre posiçôes conservadoras e progressistas; religiosas e seculares; ruralistas e industrialistas; desenvolvimentistas e ecologistas; contendo, claro, todas as possíveis combinaçóes e rearranjos da vida ideológica brasileira. $\mathrm{O}$ arco nacional-ocidental abrange tanto as propostas nacional-desenvolvimentistas do campo dito progressista quanto as plataformas da bancada conservadora da Bala, do Boi e da Bíblia, pois cada uma dessas correntes políticas e ideológicas confeccionam uma equivalência própria para os significantes "Brasil" e "Ocidente". Também abrange todo o debate existente na crítica literária e cultural brasileiro sobre a modulação nacional da cultura ocidental, que nada mais é que a racionalização erudita desse sistema de possibilidades, na eterna investigação sobre como podemos ser nacionais e singulares sem deixarmos de sermos "universais" e ocidentais.

Voltando à questão de uma nova estruturação para os estudos póscoloniais brasileiros, é preciso pontuar que talvez a tarefa máxima desse campo de estudos seja, com o perdáo da redundância, o de mostrar que há mais mundos possíveis que os espaços possíveis apresentados por esse sistema nacional-ocidental de possibilidades, cuja dinâmica maior é a de neutralizar qualquer vislumbre de alternativa que não seja de antemão previsto e regulado 
pelo próprio sistema. Os estudos pós-coloniais no Brasil deveriam se debruçar sobre tudo aquilo que é exterioridade à pretensa totalidade nacional-ocidental, e como o "fora" tem que ser por vezes neutralizado a fim de ser traduzido para os termos de "dentro".

\section{A prosa da contra-insurgência preventiva}

Vejamos um exemplo: a Rebeliāo de Canudos. Os conselheiristas representavam uma ameaça tanto para o esteio oligárquico fincado no latifúndio e na Igreja, quanto para os modernizadores da República. A ida de cada vez mais sertanejos à cidade construída pelos seguidores de Antonio Conselheiro diminuía o número de braços da lavoura para os fazendeiros e de almas para a Igreja, gerando um descontentamento que acabaria por gerar os primeiros ataques a Canudos por parte da Força Pública baiana. Já em relação ao Brasil urbano e ilustrado, Canudos foi primeiramente visto como um motim monárquico que precisava ser aniquilado por mobilização militar, e depois, graças à ágil pena de Euclides da Cunha, passou a ser retratado como um "refluxo da história", fruto do messianismo atávico dos rudes patrícios, que mereciam um tratamento diferente daquele que lhes fora dispensado pelo Exército brasileiro. As razóes principais da rebelião - a oposição à República, à vida secular, e aos impostos cobrados pelo governo - passavam a ocupar um papel secundário frente à explicaçáo ilustrada para os eventos ocorridos Canudos, que os via como sintoma de um povo ignorante e abandonado pelo Estado moderno. A violência hermenêutica merece ser destacada, pois a Rebelião é decodificada pela visão nacional-ocidental de Euclides da Cunha exatamente como o contrário daquilo que os seus atores propunham. Da revolta de um grupo social que queria se desgarrar da nação e suas instituiçóes modernas, o acontecimento passa a ser interpretado como auge da orfandade de um povo que foi deixado ao léu pelas estruturas governamentais. A explicação ilustrada-paternalista de Canudos desfaz e neutraliza a real intenção política dos conselheiristas, transformando-os em algo que é seu exato contrário, isto é, em órfãos do Estado brasileiro, deixando-os numa situaçáo que clamava por acolhimento estatal e integração ao mundo moderno.

Numa tentativa de recuperar a história da Rebelião de Canudos a partir dos Estudos Subalternos, Adriana Johnson argumenta que a frequente alusão a um povo abandonado, precisando ser urgentemente resgatado pelo Estado-Nação, é uma representação tecida pela cidade letrada brasileira. Segundo Jonhson, longe de estarem reclamando de um abandono do Estado brasileiro, os rebelados estariam lutando contra uma incorporação forçada ao Brasil moderno: 
Reading the incidents concerning Canudos (and da Cunha as the medium of their message) as a protest against abandonment is deeply problematic. Abandonment by whom? To what? If measures such as increased taxation, the secularization of daily life, the census, and mapping numbered among the causes of the conflict, then the Conselheiristas seem to have been protesting not so much abandonment as the forced incorporation into a modern-state that they perceived to be an illegitimate power extending and deepening its structures of domination. To the extent that the Conselheiristas were combating precisely such an incorporation, da Cunha's solution would have sounded like a punishing sentence of condemnation (2010, p. 137).

Ainda de acordo com Johnson, o texto de Euclides teria como objetivo corrigir - ao invés de impugnar - as açóes do Estado brasileiro moderno (2010, p. 9).

A Rebelião de Canudos mostra como um evento que se desgarra do arco nacional-ocidental (fragmento que se recusa a pertencer a uma totalidade), precisa ter sua radicalidade devidamente filtrada e neutralizada, para só assim ser traduzido como um acontecimento que se enquadre nas narrativas que buscam integrar o sertanejo ao Estado moderno nacional. Que a Rebeliáo de Canudos, tal como narrada por Euclides da Cunha, seja vista como deflagradora de uma consciência cívica nacional atesta o quanto a operação discursiva foi muito bem-sucedida.

Esse processo de filtragem e neutralização das demandas de revoltas subalternas faz parte daquilo que Ranajit Guha chama de "prosa da contrainsurgência” (GUHA, 1998). Ao narrar a revolta empregando o vocabulário da imaginação política ocidental, as elites letradas nada conseguem enxergar na revolta além de comportamento pré-político, irracional e inconsequente, legitimando assim qualquer ação que retifique o curso da rebelião e controle seus efeitos inesperados. No Brasil, as populaçóes rebeladas de Canudos entraram para história nacional e cívica num tom paternalista-ilustrado que as enxerga como sintoma de uma parte da população que, por estar aquém da política, precisa ser urgentemente integrada à nação. É possível constatar a persistência e efetividade desse discurso quando lemos, num ensaio escrito por ocasião do centenário da publicação de Os sertóes, Celso Furtado replicar, mais uma vez, a interpretação na qual "em nosso país há uma imensa população amorfa, de raízes culturais múltiplas, sendo caldeada e ascendendo progressivamente à cidadania. $\mathrm{O}$ mitológico sertanejo euclidiano deve ser visto como a prefiguração do cidadão consciente que hoje se afirma."(FURTADO, 2002, p. 105). Reitera-se a ideia que o rebelde de Canudos é uma pré-figuração de cidadáo, apesar de toda sua luta ser contra as estruturas do Estado moderno brasileiro, ou seja, contra o pertencimento a uma suposta cidadania brasileira. 
Essas questôes talvez fiquem mais claras quando analisamos, a contrapêlo, "Literatura de dois gumes" de Antonio Candido, o texto da teoria literária produzida no Brasil que consegue de maneira mais incisiva tirar as consequências do fato de que a cultura letrada transplantada no Brasil não é somente fruto da colonização, mas agente do colonialismo. $\mathrm{O}$ texto "Literatura de dois gumes", incialmente apresentado como palestra na Universidade de Cornell, em 1966, permite entrever como se dá o mecanismo de controle da prosa de contra-insurgência. "Literatura de dois gumes" é um texto particularmente revelador porque não há nele qualquer tentativa de naturalizar a relação entre cultura brasileira e Ocidente, como acontece de maneira bastante ostensiva em "Literatura e subdesenvolvimento", texto no qual Candido afirma que o brasileiro deveria encarar "serenamente o vínculo placentário com as literaturas européias, pois ela não é uma opção, mas um fato quase natural" (1987, p. 74). Em "Literatura de dois gumes", constatamos uma atitude quase oposta, uma vez que a literatura é vista e analisada como um instrumento de dominação colonial que se impóe às demais populações. Longe de desempenhar uma função suplementar na colonização, a literatura estaria no front da conquista colonial, em "competiçáa" com as culturas dominadas. Candido destaca que letrados da época eram todos sacerdotes, juristas, funcionários, militares e senhores de terra, "obviamente identificados aos valores sancionados da civilização metropolitana”, a serviço da imposição da religião católica e da autoridade real. No entanto, mesmo quando "desprovido de aspecto ideológico ostensivo"(1987, p. 165), as letras funcionavam como "forma de disciplina mental da Europa, que deveria ser aplicada ao meio rústico a modo de instrução e defesa da civilização" (1987, p. 165). E nessa "competição cultural", a literatura se contrapunha ao "primitivismo reinante", neutralizado "o perigo da absorção pelo universo do folclore”. Não há dúvidas que no conflito entre a civilização e o primitivismo, a literatura e o folclore, Antonio Candido escolhe o primeiro polo da disputa, mas isso não o impede de constatar que havia uma luta aberta e que, em alguns momentos da história, seus resultados pareciam incertos, pois os letrados se viam acuados pelo perigo de uma hegemonia cultural não ocidental. Ao destacar um processo acirrado e competitivo de disputa por hegemonia cultural, Antonio Candido coloca em xeque qualquer noção de inevitabilidade da cultura ocidental nas Américas. Como o intuito do texto é o de mostrar os "dois gumes" da literatura, Antonio Candido ressalta que apesar de ser um instrumento de dominação, a literatura também se prestou ao papel de dar "sua voz aos que não poderiam nem saberiam falar em tais níveis de expressáo" (1987, p. 177). O circuito da prosa da contra-insurgência (preventiva) se fecha. A mesma força que ajudou a desestruturar culturas e modos de vida é aquela que se propóe a vocalizar as demandas dos oprimidos - muitos deles derrotados e sistematicamente 
explorados pela colonização -, devidamente filtradas e neutralizadas, para que elas se ajustem às regras do jogo estabelecidas pelo sistema vigente de possibilidades. Os dois gumes da literatura são, a bem da verdade, duas faces da "competição cultural", ora apresentada de modo desabrido e violento, ora mostrada como mecanismo paternalista que mistura algum tipo de solidariedade com um efetivo controle social. Destruir culturas para depois fazer-se porta-voz delas é o gesto por excelência dessa prosa de contrainsurgência (preventiva) que, por sua vez, é um instrumento fundamental para administrar as diferenças dentro do arco nacional-ocidental de possibilidades.

\section{Competição cultural e racismo}

$\mathrm{Na}$ tradição do pensamento social e da literatura do Brasil, não faltam "procuradores dos pobres" 10 . Há aqueles que advogam pelos escravos, pelos sertanejos, pelos caipiras, pela cultura afro-brasileira, etc. Não raro, tais procuradores defendem algum tipo de modernização cultural e a consequente incorporação desses povos à nação moderna. $\mathrm{O}$ caso de Joaquim Nabuco é particularmente emblemático, pois o eminente abolicionista brasileiro se vê como detentor do "mandato da raça negra", servindo assim como "advogado gratuito dos escravos e dos ingênuos" (os nascidos "livres" depois da Lei do Ventre Livre de 1871). Nabuco se coloca nessa posição por considerar que os escravos não podiam, eles próprios, lutar por seus direitos, já que seriam severamente punidos se arriscassem uma revolta. Analisando do modo mais detido, percebe-se que o receio de Nabuco é bem outro: o medo de repetirse no Brasil o que aconteceu no Haiti, isto é, uma revolução liderada por escravos. Nabuco chega a comentar que a abolição só poderia ser resultado de uma revolução, se tal revolução fosse conflagrada por cidadãos livres, "como aconteceu na França" (2000, p. 45). Doutro modo, a insurreição, caso comandada por escravos, poderia se transformar numa "vindita bárbara e selvagem de uma população mantida até hoje ao nível dos animais, e cujas paixóes, quebrando o freio do medo, não conheceriam limites no modo de satisfazer-se" (2000, p. 44). Na hipótese de os escravos assumirem o poder, toda a narrativa nacional-ocidental, em qualquer uma de suas variáveis e combinaçóes, ruiria. O país seria radicalmente outro. Os prosadores da contra-insurgência preventiva serviriam como guardióes do arco nacionalocidental, eliminando e vetando qualquer vislumbre de alternativa que não seja previsto ou traduzível pelo sistema de possibilidades vigente.

É necessário destacar o quanto ganhamos analiticamente quando passamos a compreender todas essas operaçôes de neutralizaçâo e filtragem

10 A expressão "procurador dos pobres" foi retirada de um artigo de Ana Paula Pacheco sobre Vidas secas. Verificar Pacheco, 2015. 
contidos na prosa da contra-insurgência preventiva, pois tal compreensão nos ajuda, por exemplo, a dar um sentido político mais preciso ao racismo cultural mobilizado no enquadramento dado pelas elites políticas modernizadoras ao povo brasileiro.

Vejamos um trecho de Populaçóes meridionais do Brasil de Oliveira Vianna:

Toda a evolução histórica da nossa mentalidade coletiva outra coisa não tem sido, com efeito, senão um contínuo afeiçoamento [...] dos elementos etnicamente bárbaros da massa popular à moral ariana, à mentalidade ariana, isto é, ao espírito e ao caráter da raça branca. Os mestiços superiores [...] quando vencem ou ascendem em nosso meio [...], não vencem nem ascendem como tais, isto é, como mestiços [...]. Ao invés de manterem, quando ascendem, dentro dos característicos híbridos do seu tipo, ao contrário, só ascendem quando se transformam e perdem esses característicos, quando deixam de ser psicologicamente mestiços - porque se arianizam. (p. 179).

Se substituirmos as expressóes claramente racistas e as categorias raciais como "raça branca", "moral ariana”, "mentalidade ariana” por "cultura ocidental", teríamos diante de nós um bom resumo do pensamento progressista brasileiro $^{11}$ : a ideia de que o povo brasileiro - amplamente formado por matrizes demográficas e culturais não ocidentais -, quando se modernizar, será inequivocamente ocidental no pensamento e nos hábitos, ainda que mestiço, negro, ou índio, no fenótipo. A vitória de um negro (ou de um índio) no Brasil jamais será a conquista das culturas afro-brasileiras ou ameríndias no Brasil, mas um sinal de sucesso de negros ou de índios ocidentalizados.

Podemos encontrar um exemplo novamente em Joaquim Nabuco, grande defensor do abolicionismo, para quem emancipação dos escravos seria um passo imprescindível na entrada do Brasil ao mundo moderno. A defesa da abolição não impede Nabuco de demonstrar um imenso desprezo pela cultura dos escravos. Para Nabuco, a "raça negra" teria "um desenvolvimento mental atrasado", e seria detentora de "instintos bárbaros" e "superstiçôes grosseiras” (NABUCO, 2000, p. 145). Em outras palavras: a integração do negro à nova ordem social seria necessária e benvinda, desde que isso não implicasse a valorização e integração da corruptora cultura negro-brasileira na vida espiritual brasileira. O negro deveria entrar na pólis brasileira como uma tábula rasa, despojado de seu estoque cultural inicial e disposto a modernizarse e embranquecer-se culturalmente.

11 A referência a Oliveira Vianna não é gratuita. Considerado um intérprete maldito do Brasil, a um só tempo racista e autoritário (BRESCIANI, 2005), a passagem selecionada mostra que, debastado os excessos retóricos do racismo biológico, o argumento poderia ter saído da pena de um escritor progressista. A mudança aí seria apenas de racismo: do biológico passaria para um argumento repleto de racismo cultural. 
Já Euclides da Cunha conclama, nOs sertóes, os brasileiros do litoral a resgatarem os "retardatários" sertanejos (que, como já vimos, não queriam ser resgatados por ninguém). A solidariedade aos "rudes patrícios" vem sempre acompanhada da constatação da irrelevância e inferioridade de seu pensamento. Resgatar os sertanejos implica retirá-los da sua cultura bárbara e inseri-los na civilização.

Caio Prado Jr., fundador do marxismo brasileiro, por sua vez, faz um contraponto entre a escravidão dos antigos romanos e a dos brasileiros para notar que, no primeiro caso, os escravos tinham o mesmo nível cultural dos senhores, sendo capazes de ensinar muito aos romanos. Já os escravos no Brasil, "povos bárbaros e semibárbaros", não passavam de "simples máquina de trabalho bruto e inconsciente" (PRADO JR, 2000, p. 284). O negro aqui aparece novamente como tabula rasa, a ser preenchido por um conteúdo político que transforme o seu protagonismo na história brasileira. No final de Formação do Brasil contemporâneo, Caio Prado afirma que os escravos só não agiram de modo mais consequente para construir um antagonismo real contra os senhores proprietários porque "falavam na linguagem mais familiar e acessível que lhes vinha das florestas, das estepes, das savanas" (2000, p. 386). Muito diferente seria a atuaçáo dos escravos se pudessem usar a linguagem política moderna do Iluminismo, isto é, se tivessem sido "preenchidos" por conteúdo político moderno.

Despojado de sua cultura precária e pobre, também deveria ser Fabiano, personagem central de Vidas secas de Graciliano Ramos, representado no romance como alguém incapaz de encontrar uma saída para a situação opressiva em que se encontra a partir do seu próprio repertório cultural. No romance tal saída é apontada para as forças emancipatórias da educação moderna, que teria o potencial de fornecer recursos para Fabiano se defender das opressóes perpetradas por seu patrão e pelo soldado amarelo. Deixados por contra própria, isto é, guiando-se pela imaginação bronca dos sertanejos, esse povo poderia encontrar saídas irracionais para os seus problemas, como verificamos na grosseira avaliação que Graciliano faz dos rebelados de Canudos na sua "Pequena história da República", chamando-os de "lunáticos", "analfabetos", e "pior canalha da raça" (RAMOS, 2011, p. 165).

Já Monteiro Lobato, no seu Problema Vital - livro que inaugura sua segunda interpretação do Jeca Tatu - advoga a tese de que o caipira não é um doente, mas está doente. E para curar o seu mal, uma série de modificaçōes no seu ambiente deveriam ser realizadas, nas áreas do saneamento, educação, nutriçáo, higiene, etc. Todas mudanças focavam sobretudo numa reprogramação da cultura caipira, com vistas a torná-la compatível com os hábitos modernos de trabalho e produção. 
Para o grande economista progressista Celso Furtado, também despojado de sua irracionalidade econômica deveria ser o negro recém-saído da escravidão. Analisando a situação do mercado de trabalho nas regióes de maior dinamismo econômico do país logo após a Abolição, Furtado critica a falta de racionalidade econômica dos ex-escravos que, em razão do seu "rudimentar desenvolvimento mental"(FURTADO,1998, p. 144), não conseguiam aproveitar a oportunidade de receber "salários relativamente elevados" (1998, p. 144) para se manterem em atividade nas ricas regióes cafeeiras. Isso se dava porque ao receber o salário, e tendo vivido sob escravidáo por boa parte de suas vidas, os ex-escravos resolviam "comprar o ócio", reduzindo assim o "grau de utilizaçáo da força de trabalho" (1998, p. 145). Furtado argumenta que o "reduzido desenvolvimento mental da população submetida à escravidão" (FURTADO, 1998, p. 145), provocaria "a segregação parcial desta [população] após a abolição, retardando a sua assimilação e entorpecendo o desenvolvimento econômico do país" (FURTADO, 1998, p. 145). Donde se conclui que ao incutir uma racionalidade capitalista nos ex-escravos e seus descendentes, o país maximizaria um de seus fatores de produção e isso contribuiria para o desenvolvimento da nação.

Em todos esses casos - e muitos outros exemplos poderiam ser dados a cultura do povo a ser "modernizado" precisa ser descartada para algum tipo de projeto nacional-ocidental se viabilizar. Para a nação formar-se, dentro dos parâmetros nacionais-ocidentais, ela precisa seguir alguns caminhos, ao mesmo tempo que necessita rechaçar claramente outros trajetos. È necessário estudar com um recorte pós-colonial aquilo que na tradição do pensamento brasileiro chama-se "a ideia da formaçáo". Em outras palavras, tão importante quanto apreender qual o país a elite intelectual gostaria de construir, é examinar que outras possibilidades (outros devires) de Brasil tal elite nega, desqualifica, despreza, e como o imbricamento entre essas duas virtualidades - o devir desejado e o devir rejeitado para o país - está ligado a uma visão hierárquica de culturas, segundo a qual, algumas delas (as europeias) nos ajudarão a adentrar na modernidade em detrimento de outras, inferiores, menos elaboradas, que nos impediriam de chegar lá, ou nos manteriam aprisionados num atraso vergonhoso.

\section{Conclusão}

Numa das críticas mais contundentes ao Orientalismo de Edward Said, o intelectual indiano Aijaz Ahmad identifica no seu argumento central um suposto ecletismo teórico que limitaria bastante o potencial crítico do livro. Ahmad enxerga no Orientalismo uma mistura de humanismo de sabor auerbachiano revelado na perceptível apreciação estética dos grandes autores com uma abordagem foucaultiana centrada no nexo entre poder 
e conhecimento, de extração notoriamente anti-humanista. Um exemplo dado por Ahmad é a análise saidiana do escritor Ruyard Kipling. Elogiado extensivamente por sua habilidade estilística, comparável a dos maiores nomes da literatura (Proust é citado por Said como ponto de referência nessa comparação), Kipling é, num segundo momento, extremamente criticado por sua ideologia imperialista. Ahmad identifica esse morde-assopra de Said como um problema de construção teórica.

Longe de reproduzir essa perspectiva de Ahmad, intolerante em relação a qualquer esforço teórico diferente do seu, vejo vantagens no modelo de análise cultural saidiano. Afinal, tal modelo parte do pressuposto de que o texto é capaz de criar um mundo robusto, denso e nuançado, digno de apreciação, ao mesmo tempo que também localiza o texto no mundo, influenciado pelas diversas forças sociais, além de compor e legitimar estruturas de poder. A ambiguidade central da obra de Said parece estar na afirmação de que aqueles mesmos textos que apreciamos por sua complexidade conceitual, intricado artesanato verbal e sofisticação analítica são também os que azeitam a tenebrosa máquina de dominação imperialista. A análise saidiana nos permite entrar num território complexo, onde apreciamos esteticamente um escritor politicamente odioso.

Talvez essa zona de ambivalência seja um terreno analítico propício para examinar também os dilemas do nacional-ocidentalismo, sobretudo seu espectro progressista. Se a minha hipótese de trabalho estiver correta, a de que, no afấ de construir o Brasil moderno, os intelectuais valorizam um certo devir-ocidental (termo sempre em disputa) em detrimento de outros devires, uma ambiguidade precisa ser notada: os grandes pensadores progressistas, lutando contra o atraso e seus correlatos - a escravidão, o coronelismo, o subdesenvolvimento, a miséria, etc. - para libertar o povo brasileiro de sua subalternidade, acabaram também por reproduzir lógicas de colonialidade, já que hierarquizaram culturas, negando a potencialidade transformadora das não ocidentais e optaram por um roteiro emancipatório que tinha a modernidade europeia como desejado ponto de chegada.

Tal constatação não deve servir para julgar moralmente esses personagens históricos, nem tampouco macular a admiração merecida da qual muitos são objetos por suas atuações políticas em momentos importantes da história brasileira. A crítica dos pressupostos eurocêntricos contidas no pensamento progressista brasileiro deve sobretudo desnudar lógicas implícitas nessas práticas intelectuais. Não podemos exigir outro posicionamento de autores cujo horizonte intransponível era o nacional-ocidentalismo e suas possibilidades. Seria de um anacronismo terrível exigir outra sensibilidade em autores como Jósé Bonifácio, Joaquim Nabuco, Euclides da Cunha, Caio Prado e tantos outros. No entanto, ninguém pode negar que todo o senso comum do 
nacional-ocidentalismo é sedimentado e adensado por várias geraçóes de intelectuais que construíram esse arco de possibilidades a ponto de tornálo nossa segunda natureza, o ar ideológico que respiramos. Explicitar os mecanismos de colonialidade (hierarquização e subalternização de culturas e modos de vida) nessas grandes obras é fundamental para desnaturalizar os seus pressupostos, questionar os "vínculos placentários" entre o Brasil e o Ocidente, e descortinar outros horizontes possíveis - além das possibilidades apresentadas pelo sistema - para ser, estar no mundo e conceber a vida.

Referências

ANDRADE, Mário. A lição do amigo. Rio de Janeiro: Civilização Brasileira, 1982.

ANDRADE, Oswald. Pau Brasil. São Paulo: Globo, 2000,

AUERBACH, Erich. "Filologia da literatura mundial". In: Ensaios de literatura ocidental: filologia e crítica. Trad. Samuel Titan Jr e José Mariano de Macedo. São Paulo: Editora 34, 2007.

AHMAD, Aijaz. In Theory: Nations, Classes, Literatures. Londres: Verso, 1992.

BALIBAR, Etienne. “Is there a neo-racism?” In: Balibar, Etienne \& Wallerstein, Imannuel. Race, Nation, Class. Ambiguous Identities. Londres: Verso, 1991.

BHABHA, Homi. The location of culture. London: Verso, 2000.

BOSI, Alfredo. Dialética da colonização. São Paulo: Companhia das Letras, 1992.

BRESCIANI, Maria Stella Martins. O charme da ciência e a sedução da objetividade: Oliveira Vianna entre intérpretes do Brasil. São Paulo: Editora UNESP, 2005.

CAMPOS, Haroldo. Da razão antropofágica: a Europa sob o signo da devoração, Colóquio/Letras, n. 62, 1981.

CANDIDO, Antonio. Educação pela noite. São Paulo: Ática, 1987.

CANDIDO, Antonio. Formação da literatura brasileira. Belo Horizonte: Itatiaia, 1997.

CARDOSO, Fernando Henrique. Diários da Presidência: 1995-1996. São Paulo: Companhia das Letras, 2015.

DABASHI, Hamid. Can Non-Europeans Think? Chicago: Chicago University Press, 2015.

CHAKRABARTY, Dispesh. Provincializing Europe: Postcolonial Thought and Historical Difference. Princeton: Princenton University Press, 2000.

CORONIL, Fernando. Beyond Occidentalism: Toward Nonimperial Geohistorical Categories. Cultural Anthropology 11.1: 51-87, 1996. 
CUNHA, Euclides. Os sertôes: campanha de Canudos. São Paulo: Imprensa Nacional, 2001.

FURTADO, Celso. Em busca de novo modelo. São Paulo: Paz e Terra, 2002

FURTADO, Celso. Formação econômica do Brasil. Sâo Paulo: Co. Editora Nacional, 1988.

GELLNER, Ernest. "The Mightier Pen? Edward Said and the Double Standards of Inside-Out colonialism. In: Encounters with Nationalism. Oxford: Blackwell, 1994.

GOMES, Paulo Emilio de Salles. Cinema: trajetória no subdesenvolvimento. Rio de Janeiro. Paz e Terra e Embrafilme, 1980.

GUHA, Ranajit, “The Prose of Counter-Insurgency”. In: Selected Subaltern Studies. Oxford: Oxford University Press, 1998.

HOLANDA, Sérgio Buarque. Raizes do Brasil. São Paulo: Companhia das Letras, 1995.

JOHNSON, Adriana. Sentencing Canudos: Subalternity in the Backlands of Brazil. Pittisburgh: Pittisburgh University Press, 2010.

LACLAU, Ernesto. Emancipation(s). Londres: Verso, 1996.

LYNCH, Christian "Por que pensamento e não teoria? A imaginação político-social brasileira e o fantasma da condição periférica (1880-1970). DADOS - Revista de Ciências Sociais v. 56, n. 4. p. 727-767, 2013.

MARQUES, Ivan, Modernismo em revista: estética e ideologia nos periódicos dos anos 1920. Rio de Janeiro: Casa da Palavra, 2013.

LEVINE, Robert. O sertão prometido: o massacre de Canudos. São Paulo: Edusp, 1995.

MELLO. Evaldo Cabral de. "O Abolicionismo”. In: O Itamaraty na Cultura Brasileira. Rio de Janeiro. Francisco Alves, 2002.

MERQUIOR, José Guilherme. O outro Ocidente. Presença, n.15: p. 69-85, 1990.

MIGNOLO, Walter. Local histories/Global Design: Coloniality, Subaltern Knowledge and Border Thinking. Princeton: Princeton University Press, 2000.

NABUCO, Joaquim. O abolicionismo. São Paulo: Publifolha, 2000.

NABUCO, Joaquim. Minha formação. Brasilia: Editora do Senado, 1998.

NOVAIS, Fernando. Conversa com historiadores brasileiros. Ed. José Geraldo Vinci de Moraes e José Márcio Rego. São Paulo: Editora 34, 2002.

OLIVEIRA VIANNA, Francisco. Populaçóes meridionais do Brasil. Brasília Editora do Senado, 2002. 
PACHECO, Ana Paula. "O vaqueiro e o procurador dos pobres: Vidas secas”. Revista do Instituto de Estudos Brasileiros, v. 60, p. 34-55, 2015.

PRADO JR, Caio. Formação do Brasil contemporâneo. São Paulo: Brasiliense, 2000.

PRAKASH, Gyan. Another Reason: Science and the Imagination of Modern India. Princeton: Princeton University Press, 1999.

RAMOS, Graciliano. Alexandre e outros heróis São Paulo: Record, 2011.

SANTIAGO, Silviano. Vale o quanto pesa. São Paulo: Paz e Terra, 1980.

SANTIAGO, Silviano. Literatura nos trópicos. Rio de Janeiro: Rocco, 2000,

SCHWARZ, Roberto. Sequências brasileiras: ensaios. São Paulo: Companhia das Letras, 1999.

SCHWARZ, Roberto. Que horas são? São Paulo: Companhia das Letras, 1987.

SCHWARZ, Roberto. Ao vencedor as batatas. São Paulo: Duas Cidades, 1977.

SKINNER, Quentin. Visions of Politics. Cambridge: Cambridge University Press, 2002. v. I

SPIVAK, Gayatri, A Critique of Postcolonial Reason: Toward a History of the Vanishing Present. Cambridge: Harvard University Press, 1999.

TAVAROLO, Sergio, "A tese da singularidade revisitada: desafios teóricos contemporâneos." Dados-Revista de Ciências Sociais, v. 57, n. 3, p. 633-673, 2014.

Alfredo Cesar Melo. Professor Doutor do Departamento de Teoria Literária da Universidade Estadual de Campinas (UNICAMP). De 2008 a 2013 foi professor doutor [Assistant Professor - Tenure Track] do Departamento de Literatura e Línguas Românicas da Universidade de Chicago (EUA). Formou-se em ciências sociais pela Universidade Federal de Pernambuco, em 2001, e obteve seu mestrado e doutorado em literatura hispânica na Universidade da Califórnia, em Berkeley (EUA). Coordena na UNICAMP o "Kaliban - Centro de Estudos Pós-coloniais e de Literatura Mundial”.

E-mail: alfmelo@unicamp.br 